\title{
Neoplasias do trato alimentar superior de bovinos associadas ao consumo espontâneo de samambaia (Pteridium aquilinum) ${ }^{1}$
}

\author{
Marione A. Moreira Souto ${ }^{2}$, Glaucia D. Kommers ${ }^{3 *}$, Claudio S.L. Barros ${ }^{3}$, José V.M. \\ Piazer $^{4}$, Raquel R. Rech ${ }^{2}$, Franklin Riet-Correa ${ }^{5}$ e Ana L. Schild ${ }^{6}$ \\ ABSTRACT.- Moreira Souto M.A., Kommers G.D., Barros C.S.L., Piazer J.V.M., Rech R.R., Riet-Correa \\ F. \& Schild A.L. 2006. [Neoplasms of the upper digestive tract of cattle associated with \\ spontaneous ingestion of bracken fern (Pteridium aquilinum).] Neoplasias do trato alimentar \\ superior de bovinos associadas ao consumo espontâneo de samambaia (Pteridium aquilinum). Pesquisa \\ Veterinária Brasileira 26(2):112-122. Departamento de Patologia, Universidade Federal de Santa \\ Maria, 97105-900 Santa Maria, RS, Brazil.E-mail: glaukommers@yahoo.com \\ Thirty bovine with neoplasms of the upper digestive tract (UDT) associated with spontaneous \\ ingestion of bracken fern (Pteridium aquilinum) were studied. They were from 27 farms, located in \\ the municipalities of Jaguari (23) and Nova Esperança do Sul (4), Rio Grande do Sul, Brazil. The total \\ cattle population in those farms was 1,090 and large amounts of bracken fern were found in the \\ pastures. Twenty-six of the affected cattle were cows and four were castrated males, 3-13 years of \\ age; most of them were $7-8$ years old $(46,6 \%)$. Clinical signs observed in the affected animals were \\ progressive weight loss, absence of ruminal movements, cough, dysphagia, regurgitation, halitosis, \\ diarrhea, and bloat. Less frequent signs were selective appetite, dyspnea, and salivation. Two \\ bovine died and 28 were submitted to euthanasia in advanced stage of disease and necropsied. \\ The main gross and microscopic alterations were found in identical areas of the UDT. They consisted \\ of papillomas, transforming papillomas, and squamous cell carcinomas (SCCs). Metastases of SCCs \\ to regional lymph nodes and other organs, such as liver and lungs, were also observed (18/30). \\ Twenty-nine bovine had papillomas of various sizes in several areas of the UDT. The digestive \\ papillomatosis ranged from mild (45\%), to moderate (38\%), to severe $(17 \%)$. Three developing phases \\ were observed microscopically in the examined papillomas: an early growing phase, a developing \\ phase, and a regressing phase. In 16 cases, there was malignant transformation of papillomas into \\ SCCs. The SCCs were solitary (12/30) or multiple (18/30) and were histologically well, moderately, or \\ poorly differentiated. Grouping the distribution of SCCs of larger extension in the UDT into cranial \\ region (base of the tongue, pharynx/oropharynx, and epiglottis), medial region (esophagus), and \\ caudal region (cardia and rumen), the distribution was cranial in $39 \%$, middle in $16 \%$, and caudal in \\ $45 \%$ of the cases. By the same grouping criteria, but considering the total number of times SCCs of \\ varied extensions were diagnosed in the cranial, middle, and caudal regions, the percentages \\ changed to $34 \%, 26 \%$, and $40 \%$, respectively. The epidemiological and histomorphological evidences \\ found in this study are in agreement with the observations that point out the co-carcinogenesis \\ between bovine papillomavirus type 4 infection and chemicals of bracken fern in the pathogenesis \\ of the SCCs in the UDT of cattle. However, the presence of pre-neoplastic changes and SCCs in situ \\ or in early stages of development, independently of the presence of papillomas, clearly indicates
}

${ }^{1}$ Recebido em 19 de dezembro de 2005.

Aceito para publicação em 4 de janeiro de 2006.

Realizado com auxílio financeiro do Programa de Apoio a Núcleos de Excelência (PRONEX), CNPq Proc. 661069/1997. Parte da Dissertação de Mestrado do primeiro autor.

${ }^{2}$ Programa de Pós-Graduação em Medicina Veterinária, área de concentração em Patologia Veterinária, Centro de Ciências Rurais, Universidade Federal de Santa Maria (UFSM).

\footnotetext{
${ }^{3}$ Laboratório de Patologia Veterinária, Departamento de Patologia, Centro de Ciências de Saúde, UFSM, 97105-900 Santa Maria, Rio Grande do Sul. *Autor para correspondência. E-mail: glaukommers@yahoo.com

${ }^{4}$ Inspetoria Veterinária de Jaguari, Rio Grande do Sul.

${ }^{5}$ Centro de Saúde e Tecnologia Rural, Universidade Federal de Campina Grande, Campus de Patos, 58700-000 Patos, Paraíba.

${ }^{6}$ Laboratório Regional de Diagnóstico, Faculdade de Veterinária, Universidade Federal de Pelotas, 96010-000 Pelotas, Rio Grande do Sul.
} 
the possibility of development of SCCs from normal epithelium, probably due to the direct action of the chemical carcinogens contained in bracken fern.

INDEX TERMS: Poisonous plants, Pteridium aquilinum, plant poisoning, bovine papillomavirus type 4, squamous cell carcinoma, diseases of cattle, pathology.

RESUMO.- Foram estudados 30 bovinos com neoplasias no trato alimentar superior (TAS) associadas ao consumo espontâneo de samambaia (Pteridium aquilinum) provenientes de 27 propriedades rurais, sendo 23 no município de Jaguari e quatro em Nova Esperança do Sul, Rio Grande do Sul. A população bovina total das 27 propriedades em que ocorreram os casos era de 1.090 bovinos e havia quantidade abundante de samambaia nas áreas de pastoreio dos animais. Vinte e seis bovinos eram vacas e 4 eram machos castrados. A idade variou de 3 a 13 anos, sendo o maior número de casos entre 7 e 8 anos $(46,6 \%)$. Os sinais clínicos observados incluíram emagrecimento progressivo, atonia ruminal, tosse, disfagia, regurgitação, halitose, diarréia e timpanismo. Outros sinais clínicos menos freqüientes foram apetite seletivo, dispnéia e salivação. Dois bovinos tiveram morte espontânea e 28 foram submetidos à eutanásia em estágios avançados da doença e necropsiados. Os principais achados macroscópicos e histológicos observados nos 30 bovinos localizavam-se nos mesmos locais do TAS e consistiram de papilomas, papilomas em transformação para carcinomas de células escamosas (CCEs) e CCEs. Metástases de CCEs para linfonodos regionais e outros órgãos (como fígado e pulmões) foram também observadas (18/30). Vinte e nove bovinos tinham papilomas de diversos tamanhos, sendo a quantidade variável entre leve $(45 \%)$, moderada (38\%) e acentuada (17\%). Nos papilomas examinados microscopicamente, foram observadas três fases de desenvolvimento: a) fase de inicial de crescimento, b) fase de desenvolvimento, e c) fase de regressão. Em 16 bovinos, observouse a transformação maligna de papilomas em CCEs. Os CCEs eram únicos (12/30) ou múltiplos (18/30) e variaram quanto ao grau de diferenciação celular entre bem, moderadamente ou pouco diferenciados. Quando a distribuição dos CCEs de maior extensão foi agrupada em regiões cranial (base da língua, faringe/ orofaringe, epiglote), média (terços cranial, médio e caudal do esôfago) e caudal (entrada do rúmen e rúmen) do TAS, observouse que a localização era cranial em $39 \%$ dos casos, média em $16 \%$, e caudal em $45 \%$. Utilizando-se esse mesmo critério de agrupamento, porém considerando o número total de vezes em que CCEs (de tamanhos variados) foram diagnosticados nas regiões cranial, média e caudal, os números alteraram-se para 34, 26 e $40 \%$, respectivamente. As evidências epidemiológicas e histomorfológicas relatadas neste estudo reforçam as observações de uma estreita correlação entre a infecção pelo papilomavírus bovino tipo 4 , causador da papilomatose digestiva, e a cocarcinogênese química dos princípios tóxicos da samambaia na patogênese dos CCEs do TAS de bovinos. Entretanto, a presença de alterações pré-neoplásicas (áreas de displasia), áreas de CCE in situ ou CCEs em estágios iniciais de desenvolvimento, independentemente da presença de papilomas no local, mostram claramente ser possível o desenvolvimento de CCEs diretamente do epitélio normal, possivelmente por uma ação direta dos carcinógenos químicos da samambaia.
TERMOS DE INDEXAÇÃO: Plantas tóxicas, Pteridium aquilinum, intoxicação por planta, papilomavírus bovino tipo 4 , carcinoma de células escamosas, doenças de bovinos, patologia.

\section{INTRODUÇÃO}

Pteridium aquilinum (L.) Kuhn (nomes comuns: samambaia, samambaia-do-campo, samambaia-das-taperas, pluma ou plumagrande), pertencente à família Polypodiaceae, é uma planta daninha encontrada principalmente em solos ácidos e de baixa fertilidade, infestando pastagens, solos cultivados, beira de estradas e terrenos baldios (Tokarnia et al. 1979, Lorenzi 1991). Pteridium aquilinum subsp. caudatum var. arachnoideum é a única variedade identificada no Brasil (Freitas et al. 1999, Tokarnia et al. 2000).

Três doenças que acometem bovinos têm como característica epidemiológica comum o fato de ocorrerem somente em regiões onde as áreas de pastoreio são altamente infestadas por samambaia, porém não ocorrem com a mesma freqüência em diferentes regiões. Essas doenças são: a) síndrome hemorrágica aguda (SHA) associada com aplasia de medula óssea, b) hematúria enzoótica bovina (HEB) caracterizada por hematúria e neoplasias da bexiga, e c) carcinomas de células escamosas (CCEs) no trato alimentar superior ([TAS] (Döbereiner et al. 1967, Tokarnia et al. 1967, 1969).

Foi observado que a intoxicação crônica por samambaia na forma de CCEs no TAS de bovinos tinha alta incidência somente em bovinos das terras altas ("Western Highlands") da Escócia e este fato foi associado à presença abundante de samambaia na fazendas afetadas. Adicionalmente, foi relatada uma amplificação na papilomatose digestiva de origem viral nos bovinos dessas mesmas áreas, e observou-se que muitos papilomas sofriam transformação maligna para CCEs (Jarrett 1978). Esses fatos despertaram a atenção para uma possível interação entre um carcinógeno ambiental (princípios tóxicos da samambaia) e um papilomavírus, identificado como papilomavírus bovino do tipo 4 (BPV-4), na carcinogênese dos tumores do TAS de bovinos (Jarrett et al. 1978). P. aquilinum possui vários princípios tóxicos os quais atuam como carcinógenos, mutágenos e imunossupressores (Campo 1997, 2002).

No Brasil, casos de intoxicação crônica por samambaia sob a forma de CCEs no TAS têm sido descritos e revisados por vários autores (Döbereiner et al. 1967, Tokarnia et al. 1969, Campos Neto et al. 1975, Polack 1990, França et al. 2002, Gava et al. 2002), principalmente no que diz respeito à epidemiologia e à descrição das lesões. Apesar da grande maioria desses trabalhos mencionar a ocorrência simultânea de papilomas e CCEs ao longo do TAS dos bovinos afetados, as evidências histomorfológicas da possível cocarcinogênese samambaia-BPV-4 não têm sido, ou têm sido superficialmente abordadas em estudos realizados no Brasil.

Os objetivos deste trabalho foram estudar os aspectos epidemiológicos, clínicos, macroscópicos e histológicos de 30 casos de CCEs no TAS de bovinos consumindo samambaia es- 
pontaneamente, diagnosticados no período de setembro/2003 a agosto/2005 no Laboratório de Patologia Veterinária (LPV) da Universidade Federal de Santa Maria (UFSM), com ênfase na descrição e distribuição dos papilomas e CCEs, e nas evidências histomorfológicas da interação samambaia-papilomavírus.

\section{MATERIAL E MÉTODOS}

De setembro/2003 a agosto/2005, foram estudados 30 casos de intoxicação crônica por samambaia (Pteridium aquilinum), sob a forma clínica de neoplasias no TAS de bovinos no LPV-UFSM. Os animais eram provenientes de 27 propriedades rurais (denominadas de A-Z1) dos municípios de Jaguari (23) e Nova Esperança do Sul (4), Rio Grande do Sul. Da Propriedade F, foram estudados 2 bovinos e da Propriedade $\mathrm{H}, 3$ bovinos.

Nessas propriedades, foi aplicado um questionário epidemiológico investigando os seguintes aspectos: a) número de casos da doença no ano em curso, b) número de casos da doença em anos anteriores, c) época do ano de maior ocorrência da doença, e d) ocorrência de SHA e HEB. A população bovina total de cada propriedade foi determinada por categorias (vacas, touros, bois, novilhos e bezerros). A presença da planta e o tipo de solo foram também informados.

Trinta bovinos (numerados de 1-30) com sinais clínicos indicativos de neoplasias do TAS foram avaliados clinicamente e necropsiados. Foram coletados fragmentos de tecidos do TAS incluindo palato duro, palato mole, base da língua, epiglote, faringe/orofaringe, esôfago (terços cranial, médio e caudal), entrada do rúmen e rúmen nos quais foram observadas alterações macroscópicas, além de linfonodos regionais e outros órgãos com possíveis metástases. Em áreas do TAS onde as lesões macroscópicas eram pouco definidas (alterações hiperplásicas ou neoplásicas), procedeu-se um encaminhamento dirigido, identificando-se a área encaminhada para histopatologia com letras minúsculas do alfabeto em uma fotografia da peça. A bexiga foi avaliada para verificação da ocorrência de lesões compatíveis com HEB. O encéfalo foi examinado de acordo com o Manual de Procedimentos para o Diagnóstico das Doenças do Sistema Nervoso Central de Bovinos e os animais foram enquadrados na Categoria 3 (animal com doença depauperante, crônica ou caquetizante), como parte da avaliação para o Sistema de Vigilância das Encefalopatias Espongiformes Transmissíveis do Ministério da Agricultura, Pecuária e Abastecimento do Brasil (Barros \& Marques 2003). As amostras foram fixadas em formol a $10 \%$, processadas e coradas rotineiramente para histopatologia.

A distribuição dos CCEs nas diferentes regiões do TAS foi determinada de acordo com dois critérios: a) presença de CCEs de maior extensão em centímetros, e b) presença de CCEs de menores dimensões. No estudo histológico, os CCEs foram classificados de acordo com o grau de diferenciação celular como: a) bem diferenciados, b) moderadamente diferenciados, ou c) pouco diferenciados; de acordo com os critérios de McKee (1999) e Head et al. (2002) para essa neoplasia.

\section{RESULTADOS}

\section{Epidemiologia}

Através do questionário aplicado nas 27 propriedades, verificou-se que em 11 delas haviam ocorrido 1-4 casos de CCEs no TAS de bovinos no mesmo ano de aplicação do questionário. Quatorze propriedades tiveram casos de bovinos com CCEs no TAS em anos anteriores. Em 8 fazendas a doença foi mais observada na primavera-verão, em duas no inverno, em uma durante todo o ano, e os demais proprietários não souberam informar a época de maior
Quadro 1. Neoplasias do trato alimentar superior de bovinos associadas ao consumo espontâneo de samambaia (Pteridium aquilinum). Dados de resenha e procedência dos $\mathbf{3 0}$ bovinos

\begin{tabular}{|c|c|c|c|c|c|c|}
\hline $\begin{array}{l}\text { Bovino } \mathrm{n}^{\mathrm{o}} \\
\text { (protocolo) }\end{array}$ & $\begin{array}{l}\text { Idade } \\
\text { (anos) }\end{array}$ & Sexo & Raça & $\begin{array}{l}\text { Tipo e data } \\
\text { da morte }\end{array}$ & $\begin{array}{c}\text { Propriedade } \\
\text { de origem }\end{array}$ & e Município \\
\hline $\begin{array}{c}01 \\
(\mathrm{Vn}-263-03)\end{array}$ & 4 & $\mathrm{~F}^{\mathrm{a}}$ & $\begin{array}{l}\text { Cruza } \\
\text { Holandês }\end{array}$ & $\begin{array}{c}\mathrm{ESP}^{\mathrm{b}} \\
24.09 .03\end{array}$ & A & Jaguari \\
\hline $\begin{array}{c}02 \\
n-264-03)\end{array}$ & 7 & $\mathrm{~F}$ & Mista & $\begin{array}{c}\text { EUTC }^{\mathrm{C}} \\
25.09 .03\end{array}$ & B & Jaguari \\
\hline $\begin{array}{c}03 \\
(\mathrm{Vn}-357-03)\end{array}$ & 13 & $\mathrm{~F}$ & Mista & $\begin{array}{c}25.09 .03 \\
\text { EUT } \\
20.11 .03\end{array}$ & C & Jaguari \\
\hline $\begin{array}{c}04 \\
(\mathrm{Vn}-401-03)\end{array}$ & 7 & $\mathrm{~F}$ & $\begin{array}{c}\text { Cruza } \\
\text { Charolês }\end{array}$ & $\begin{array}{c}\text { EUT } \\
19.12 .03\end{array}$ & D & Jaguari \\
\hline $\begin{array}{c}05 \\
(\text { Vn-11-04) }\end{array}$ & 6 & $\mathrm{~F}$ & Mista & $\begin{array}{c}\text { EUT } \\
15.01 .04\end{array}$ & E & Jaguari \\
\hline $\begin{array}{c}06 \\
(\mathrm{Vn}-29-04)\end{array}$ & 8 & $\mathrm{MC}^{\mathrm{d}}$ & Mista & $\begin{array}{c}\text { EUT } \\
17.02 .04\end{array}$ & $\mathrm{~F}^{\mathrm{e}}$ & Jaguari \\
\hline $\begin{array}{c}07 \\
(\mathrm{Vn}-30-04)\end{array}$ & 8 & $\mathrm{~F}$ & Holandês & $\begin{array}{c}\text { EUT } \\
17.02 .04\end{array}$ & G & Jaguari \\
\hline $\begin{array}{c}08 \\
(\mathrm{~V}-138-04)\end{array}$ & 11 & $\mathrm{~F}$ & Mista & $\begin{array}{c}\text { EUT } \\
02 / 03 / 04\end{array}$ & $\mathrm{H}^{\mathrm{e}}$ & Jaguari \\
\hline $\begin{array}{c}09 \\
\text { (V-165-04) }\end{array}$ & 9 & $\mathrm{~F}$ & Mista & $\begin{array}{c}\text { EUT } \\
05.03 .04\end{array}$ & I & Jaguari \\
\hline $\begin{array}{c}10 \\
(\mathrm{Vn}-50-04)\end{array}$ & 5 & $\mathrm{~F}$ & Mista & $\begin{array}{c}\text { EUT } \\
11.03 .04\end{array}$ & $\mathrm{H}$ & Jaguari \\
\hline $\begin{array}{c}11 \\
(\mathrm{Vn}-51-04)\end{array}$ & 5 & $\mathrm{~F}$ & Mista & $\begin{array}{c}\text { EUT } \\
11.03 .04\end{array}$ & $\mathrm{~F}$ & Jaguari \\
\hline $\begin{array}{c}12 \\
(\mathrm{Vn}-78-04)\end{array}$ & 6 & $\mathrm{~F}$ & $\begin{array}{l}\text { Cruza } \\
\text { Nelore }\end{array}$ & $\begin{array}{c}\text { EUT } \\
30.03 .04\end{array}$ & $J$ & $\begin{array}{l}\text { Nova Espe- } \\
\text { rança do Sul }\end{array}$ \\
\hline $\begin{array}{c}13 \\
(\mathrm{Vn}-80-04)\end{array}$ & 8 & $\mathrm{~F}$ & $\begin{array}{l}\text { Cruza } \\
\text { Charolês }\end{array}$ & $\begin{array}{c}\text { EUT } \\
30.03 .04\end{array}$ & $\mathrm{~K}$ & J \\
\hline $\begin{array}{c}14 \\
(\mathrm{Vn}-113-04)\end{array}$ & 7 & MC & Mista & $\begin{array}{c}\text { EUT } \\
24.04 .04\end{array}$ & $\mathrm{~L}$ & Jaguari \\
\hline $\begin{array}{c}15 \\
(\mathrm{~V}-495-04)\end{array}$ & 3 & MC & $\begin{array}{l}\text { Cruza } \\
\text { Nelore }\end{array}$ & $\begin{array}{c}\text { EUT } \\
08.06 .04\end{array}$ & $\mathrm{M}$ & Jaguari \\
\hline $\begin{array}{c}16 \\
(\mathrm{Vn}-185-04)\end{array}$ & 7 & $\mathrm{~F}$ & Mista & $\begin{array}{c}\text { EUT } \\
17.06 .04\end{array}$ & $\mathrm{~N}$ & Jaguari \\
\hline $\begin{array}{c}17 \\
(\mathrm{Vn}-221-04)\end{array}$ & 7 & $\mathrm{~F}$ & $\begin{array}{l}\text { Cruza } \\
\text { Charolês }\end{array}$ & $\begin{array}{c}\text { EUT } \\
13.07 .04\end{array}$ & $\mathrm{O}$ & Jaguari \\
\hline $\begin{array}{c}18 \\
(\mathrm{~V}-637-04)\end{array}$ & 11 & MC & Mista & $\begin{array}{c}\text { EUT } \\
26.07 .04\end{array}$ & $\mathrm{P}$ & Jaguari \\
\hline $\begin{array}{c}19 \\
(\mathrm{Vn}-300-04)\end{array}$ & 7 & $\mathrm{~F}$ & Mista & $\begin{array}{c}\text { EUT } \\
08.09 .04\end{array}$ & 0 & Jaguari \\
\hline $\begin{array}{c}20 \\
(\mathrm{Vn}-302-04)\end{array}$ & 10 & $\mathrm{~F}$ & Mista & $\begin{array}{c}\text { EUT } \\
08.09 .04\end{array}$ & $\mathrm{R}$ & $\begin{array}{l}\text { Nova Espe- } \\
\text { rança do Sul }\end{array}$ \\
\hline $\begin{array}{c}21 \\
(\mathrm{Vn}-305-04)\end{array}$ & 8 & $\mathrm{~F}$ & Mista & $\begin{array}{c}\text { EUT } \\
14.09 .04\end{array}$ & $S$ & Jaguari \\
\hline $\begin{array}{c}22 \\
(\mathrm{Vn}-366-04)\end{array}$ & 10 & $\mathrm{~F}$ & Mista & $\begin{array}{c}\text { EUT } \\
04.11 .04\end{array}$ & $T$ & Nova Espe- \\
\hline $\begin{array}{c}23 \\
(\mathrm{Vn}-367-04)\end{array}$ & 8 & $\mathrm{~F}$ & Mista & $\begin{array}{c}\text { ESP } \\
05.11 .04\end{array}$ & $\mathrm{U}$ & Jaguari \\
\hline $\begin{array}{c}24 \\
(\mathrm{Vn}-373-04)\end{array}$ & 9 & $\mathrm{~F}$ & Mista & $\begin{array}{c}\text { EUT } \\
08.11 .04\end{array}$ & V & Jaguari \\
\hline $\begin{array}{c}25 \\
(\mathrm{Vn}-428-04)\end{array}$ & 9 & $\mathrm{~F}$ & Mista & $\begin{array}{c}\text { EUT } \\
21.12 .04\end{array}$ & W & Jaguari \\
\hline $\begin{array}{c}26 \\
(\mathrm{~V}-431-05)\end{array}$ & 8 & $\mathrm{~F}$ & Jersey & $\begin{array}{c}\text { EUT } \\
04.05 .05\end{array}$ & $\mathrm{X}$ & Jaguari \\
\hline $\begin{array}{c}27 \\
(\mathrm{~V}-475-05)\end{array}$ & 13 & $\mathrm{~F}$ & Aist & $\begin{array}{c}\text { EUT } \\
18.05 .05\end{array}$ & $\mathrm{H}$ & 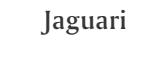 \\
\hline $\begin{array}{c}28 \\
(\mathrm{~V}-476-05)\end{array}$ & 8 & $\mathrm{~F}$ & Mista & $\begin{array}{c}\text { EUT } \\
16.05 .05\end{array}$ & $\mathrm{Y}$ & Jaguari \\
\hline $\begin{array}{c}29 \\
(\mathrm{~V}-507-05)\end{array}$ & 6 & $\mathrm{~F}$ & ista & $\begin{array}{c}\text { EUT } \\
24.05 .05\end{array}$ & Z & Jaguari \\
\hline $\begin{array}{c}30 \\
\text { (V-666-05) }\end{array}$ & 8 & $\mathrm{~F}$ & Mista & $\begin{array}{c}\text { EUT } \\
01.08 .05\end{array}$ & $\mathrm{Z} 1$ & $\begin{array}{l}\text { Nova Espe- } \\
\text { rança do Sul }\end{array}$ \\
\hline
\end{tabular}

aFêmea, bespontânea, ' eutanásia, d ${ }^{\mathrm{d}}$ macho castrado, ${ }^{\mathrm{e}}$ propriedade com mais de um bovino remetido. 
ocorrência da doença. Seis propriedades tiveram casos de HEB. A SHA não foi relatada pelos proprietários. A presença abundante de samambaia nas áreas de pastoreio dos bovinos estudados foi

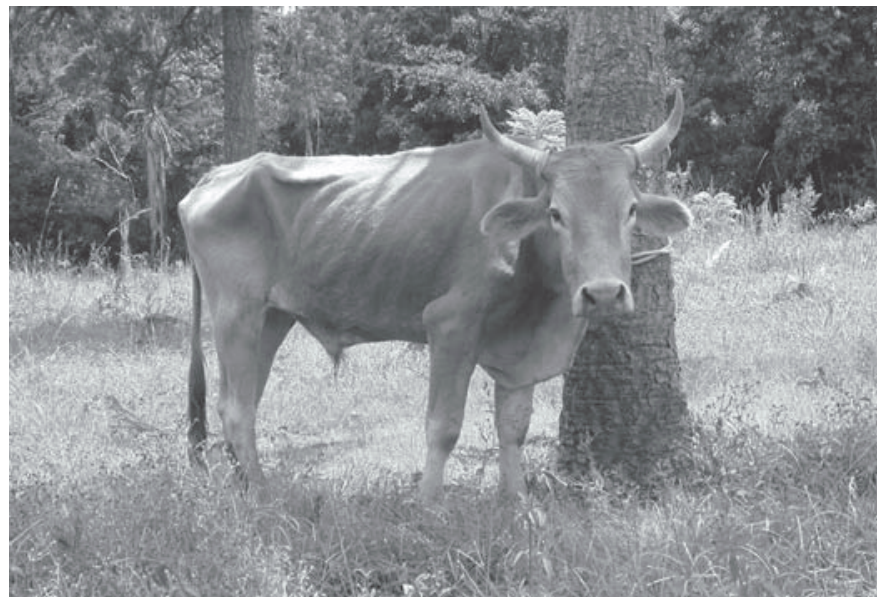

Fig.1. Emagrecimento acentuado por processo neoplásico no trato alimentar superior associado ao consumo espontâneo de samambaia, Pteridium aquilinum (Bovino 6).
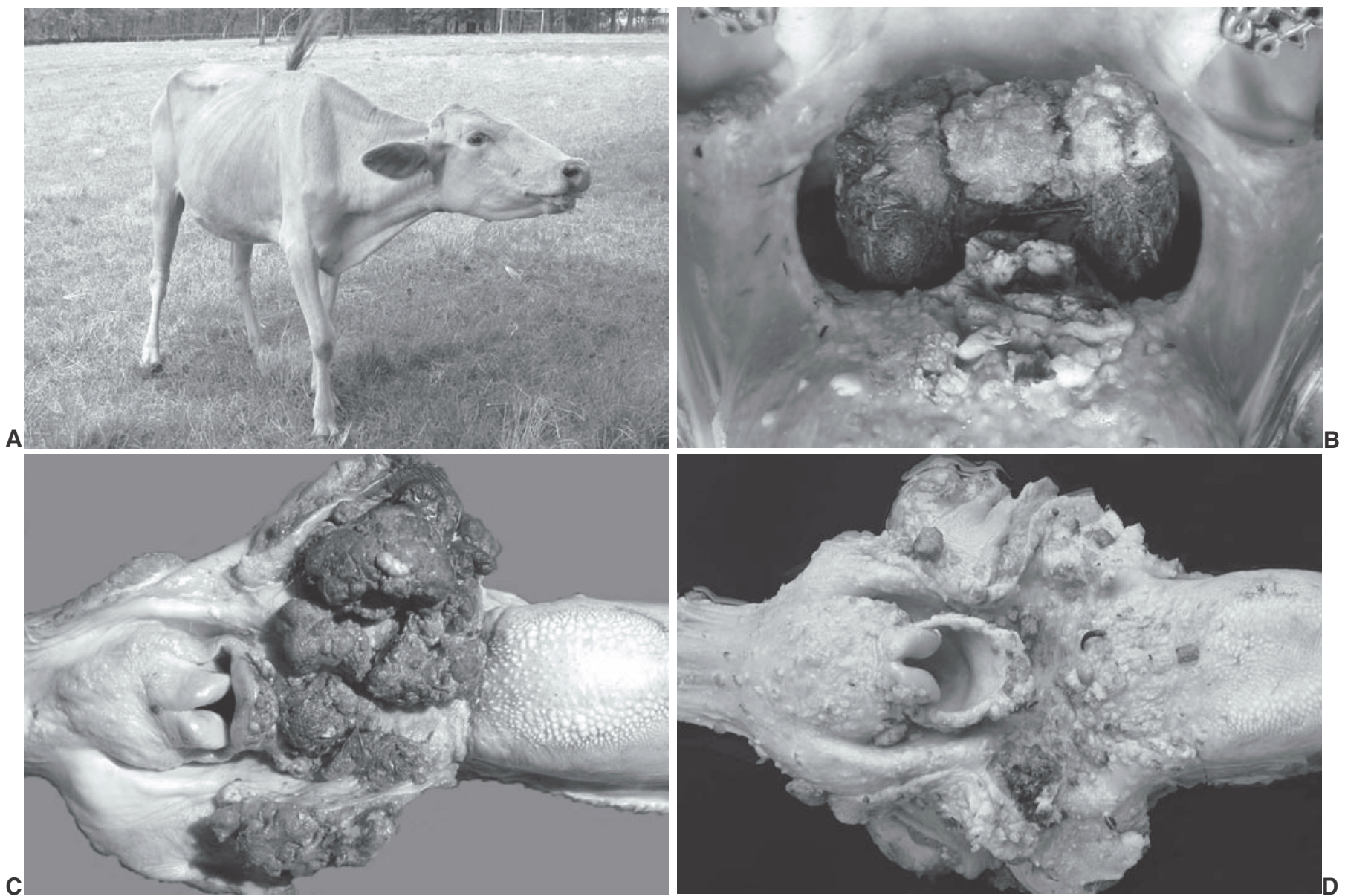

Fig.2. Neoplasias do trato alimentar superior de bovinos associadas ao consumo espontâneo de samambaia, Pteridium aquilinum. A. Tosse e distensão do pescoço devido à carcinoma de células escamosas (CCE) na epiglote (Bovino 10). B. CCE exofítico e pedunculado na base da língua; há papilomas cranialmente ao CCE (Bovino 17). C. CCE exofítico na faringe/orofaringe (Bovino 6). D. Papilomatose acentuada na região cranial do trato alimentar superior (Bovino 4). 

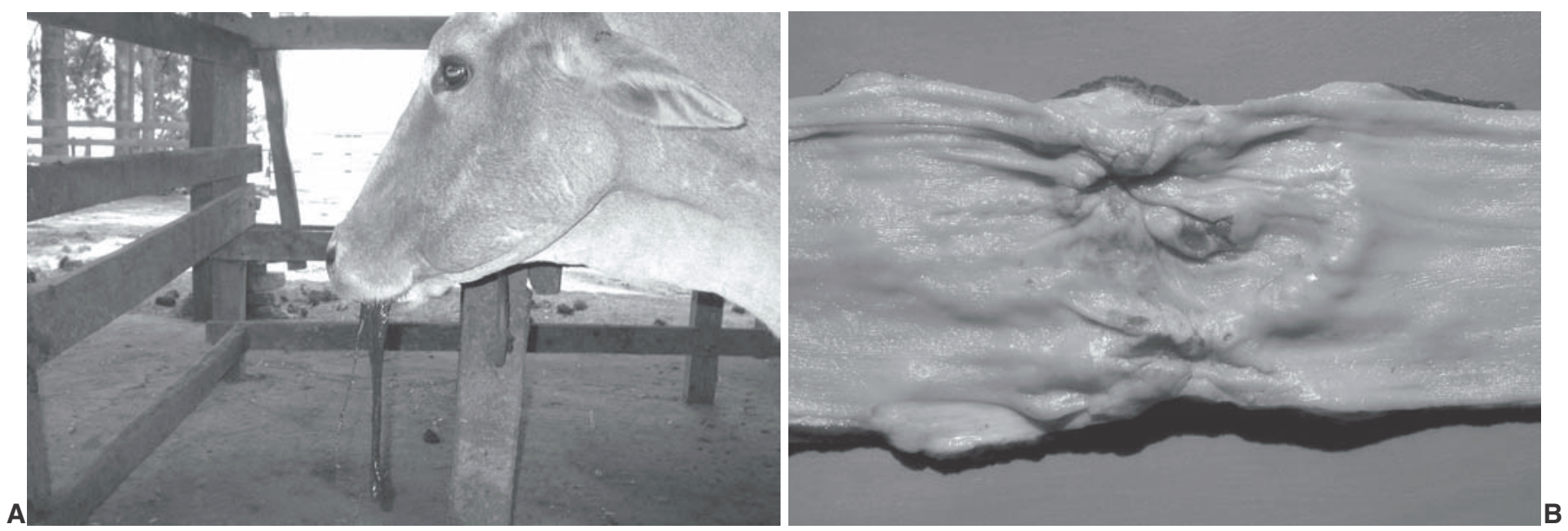

Fig.3. Neoplasias do trato alimentar superior de bovinos associadas ao consumo espontâneo de samambaia, Pteridium aquilinum. A. Regurgitação de conteúdo alimentar (Bovino 13). B. Espessamento estenosante anelar correspondendo a um carcinoma de células escamosas, parcialmente ulcerado, no terço médio do esôfago (Bovino 25).

$30)$, tosse (17/30), disfagia (12/30), regurgitação $(12 / 30)$, halitose (10/30), diarréia (9/30), timpanismo (8/30), apetite seletivo (7/30), dispnéia (3/30) e salivação (3/30). O emagrecimento acentuado (Fig.1) foi o sinal clínico apresentado constantemente pelos bovinos examinados. Atonia ruminal foi um sinal clínico freqüente, com duração variável, e observada em bovinos com CCEs em várias localizações no TAS; porém na metade dos casos (10/20) o CCE localizava-se no rúmen (na entrada ou estendendo-se numa distância de $15-30 \mathrm{~cm}$ a partir da entrada do rúmen). A tosse, muitas vezes acompanhada por distensão do pescoço (Fig.2A), foi observada freqüentemente (10/17) em bovinos com CCEs na área cranial do TAS [base da língua (Fig.2B), faringe/orofaringe (Fig.2C), esôfago e epiglote]. Bovinos com CCEs em outras localizações, porém com papilomatose acentuada na área cranial (Fig.2D), também apresentaram tosse.

A disfagia foi observada principalmente nos bovinos com CCEs na base da língua e faringe/orofaringe (6/12). Regurgitação freqüiente (Fig.3A) foi vista em bovinos com CCEs localizados principalmente no esôfago (Fig.3B) e entrada do rúmen (8/12).
Halitose (hálito com odor pútrido) foi observada em bovinos com CCEs localizados principalmente na base da língua e faringe/ orofaringe (7/10), freqüentemente associada à presença de extensa necrose do CCE e impactação de alimentos nas porções proximais às áreas afetadas. Timpanismo (Fig.4A) de intensidade e duração variáveis, foi mais marcado em bovinos com CCEs na entrada do rúmen (5/8, Fig.4B), muitas vezes associados com acentuado edema da mucosa da região levando à obstrução parcial. Os outros 3 bovinos com timpanismo tinham espessamentos estenosantes anelares correspondentes a CCEs desmoplásicos da parede esofágica (Fig.3B) ou tinham CCE associado com impactação de alimentos no esôfago.

Os principais achados macroscópicos e histológicos observados no TAS dos 30 bovinos consistiam de papilomas, papilomas em transformação para CCEs, CCEs e metástases de CCEs para linfonodos regionais e outros órgãos. Vinte e nove bovinos (97\%) tinham papilomas de tamanhos variados $(0,2-2 \mathrm{~cm}$ de diâmetro), únicos ou múltiplos, sésseis ou pedunculados, com projeções digitiformes conspícuas e queratinização superficial variável
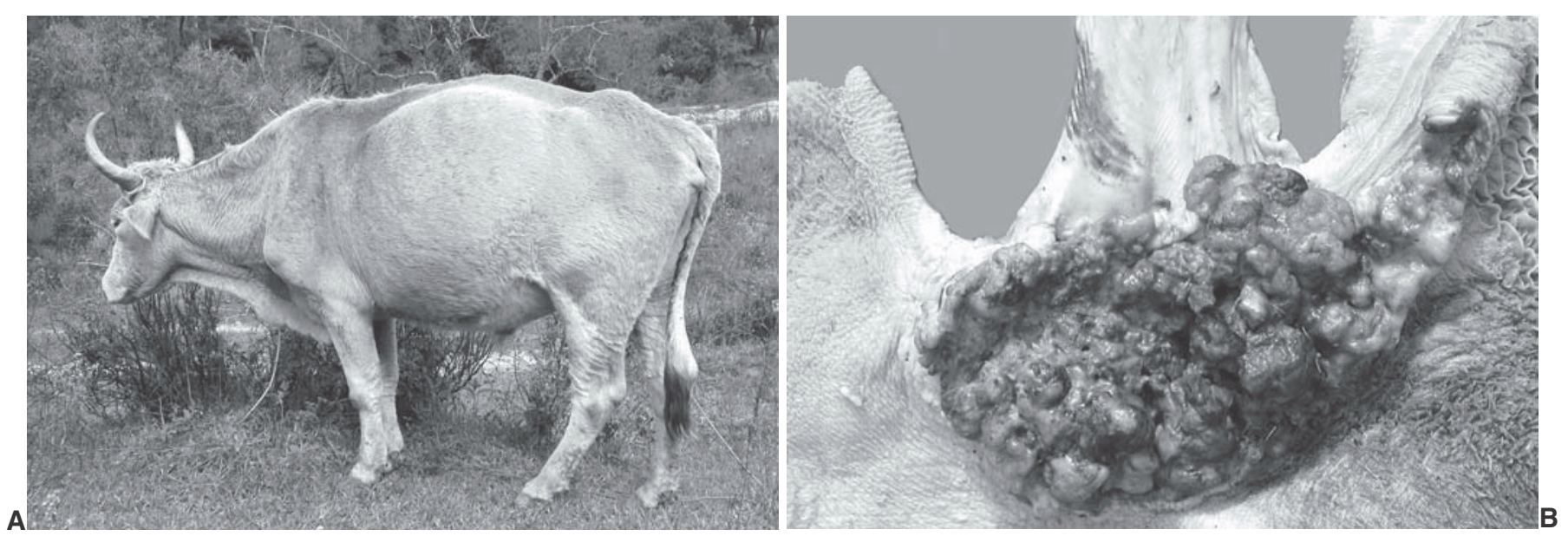

Fig.4. Neoplasias do trato alimentar superior de bovinos associadas ao consumo espontâneo de samambaia, Pteridium aquilinum. A. Timpanismo acentuado (Bovino 14). B. Carcinoma de células escamosas na entrada do rúmen (Bovino 16). 


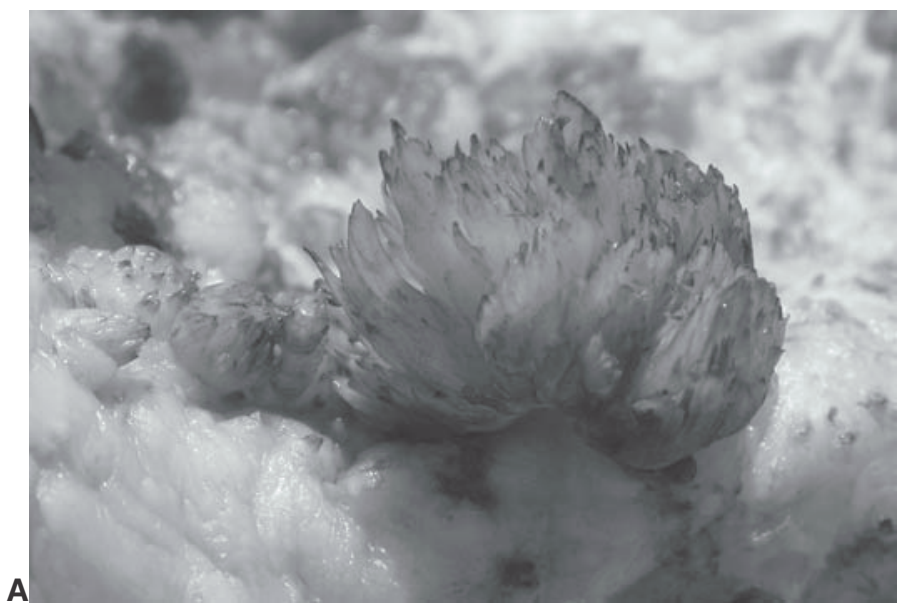

Fig.5. Neoplasias do trato alimentar superior de bovinos associadas ao consumo espontâneo de samambaia, Pteridium aquilinum. A. Papiloma pedunculado na faringe (Bovino 24). B. Fase de desenvolvimento de um papiloma pedunculado; aspecto submacroscópico (Bovino 28). HE, obj.2,5. C. Papiloma em fase de regressão com atenuação das projeções digitiformes; aspecto submacroscópico (Bovino 26). HE, obj.2,5.

(Fig.5A). O Bovino 1 não tinha papilomas no TAS. Os papilomas foram observados no palato duro (3/29), palato mole (18/29), base da língua (20/29), faringe/orofaringe (24/29), epiglote (8/ 29), esôfago (terços cranial [15/29], médio [14/29] e caudal [14/ 29]), entrada do rúmen (26/29) e rúmen (6/29). O grau de papilomatose nos diferentes locais do TAS variou entre leve (até 10 papilomas, $45 \%$ ), moderada (10-20 papilomas, $38 \%$ ) e acentuada (mais de 20 papilomas, $17 \%$ ). Apenas o Bovino 30 tinha um papiloma na mucosa da bexiga.

Histologicamente, os papilomas eram constituídos por projeções digitiformes revestidas por epitélio escamoso estratificado hiperplásico com queratinização superficial variável, sustentadas por eixos fibrovasculares centrais. Nas camadas superiores do estrato espinhoso havia células com núcleos pequenos, hipercromáticos e excêntricos, circundados por um halo claro perinuclear, morfologicamente compatíveis com coilócitos. Fo-
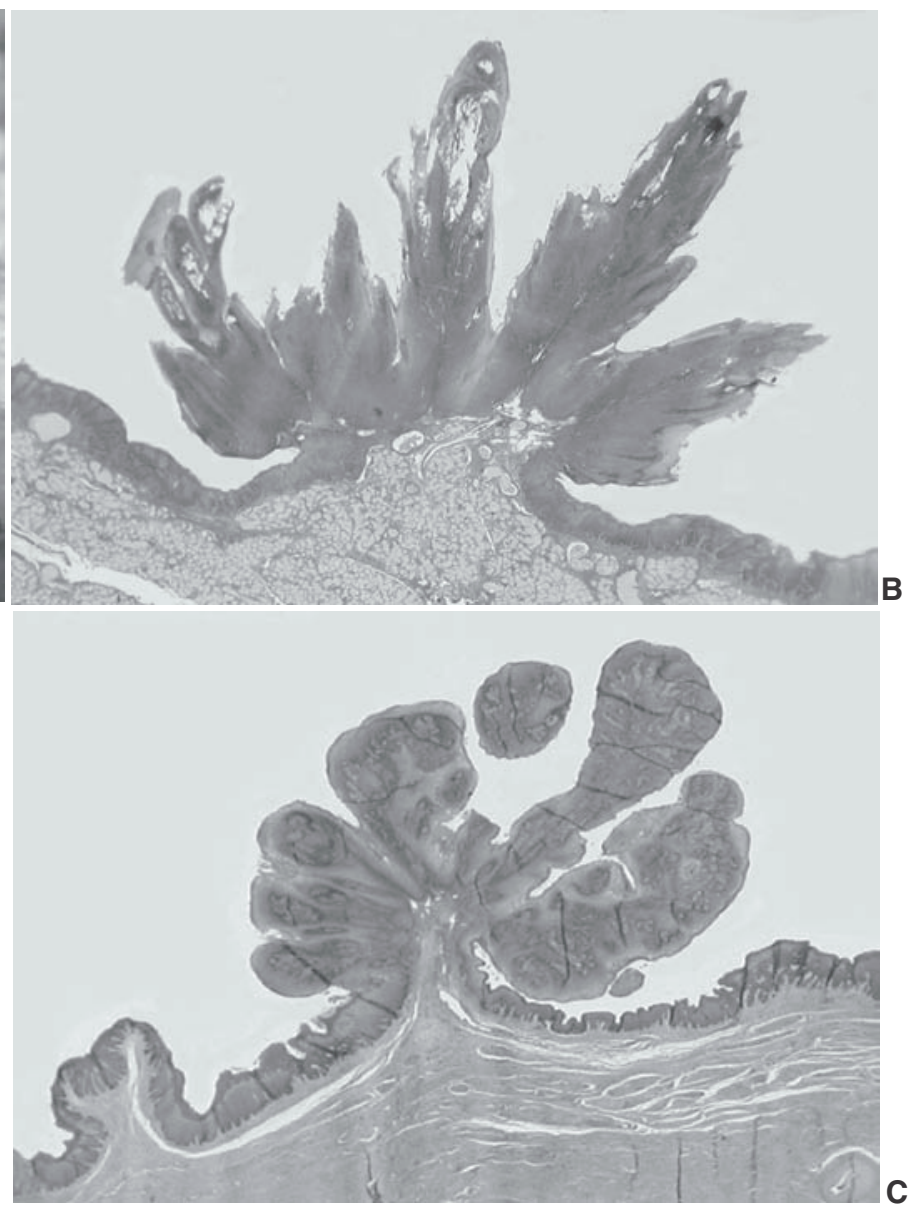

ram observadas três fases distintas de desenvolvimento dos papilomas microscopicamente: a) fase inicial de crescimento, b) fase de desenvolvimento, e c) fase de regressão. Os papilomas em fase inicial de crescimento caracterizavam-se por hiperplasia das células epiteliais formando placas ou projeções digitiformes curtas, correspondendo macroscopicamente a pequenas elevações rugosas na mucosa. Os papilomas em fase de desenvolvimento (Fig.5B) caracterizavam-se por marcada hiperplasia epitelial com tumefação celular, hiperqueratose ortoqueratótica
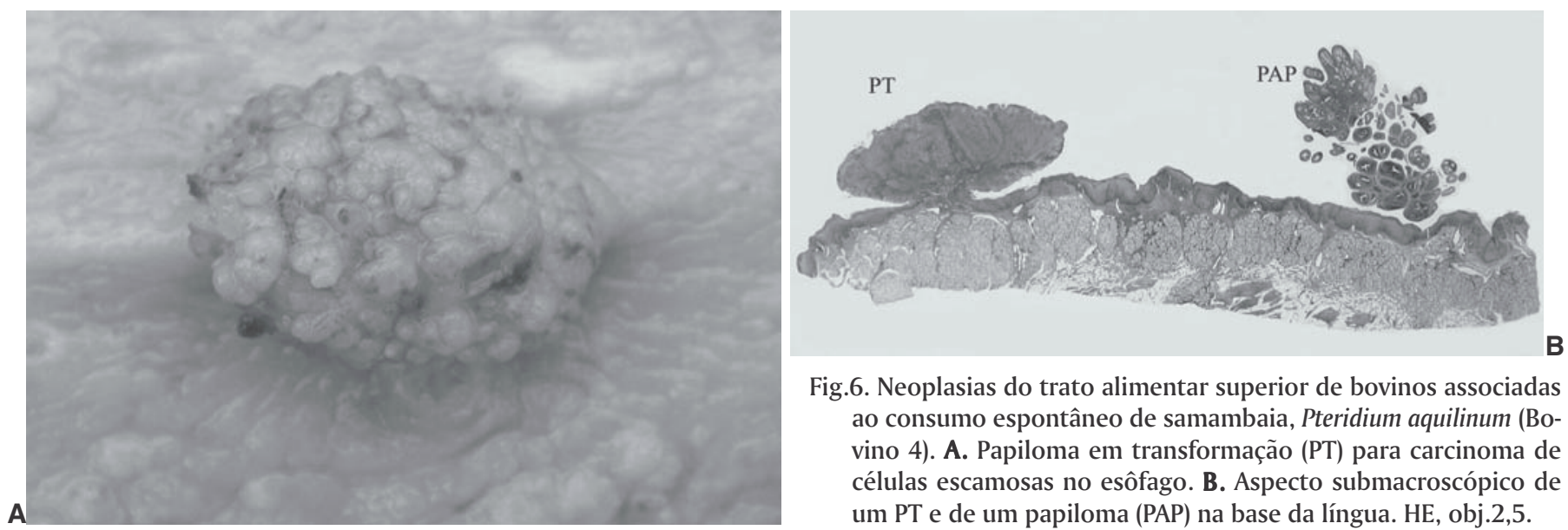

Fig.6. Neoplasias do trato alimentar superior de bovinos associadas ao consumo espontâneo de samambaia, Pteridium aquilinum (Bovino 4). A. Papiloma em transformação (PT) para carcinoma de células escamosas no esôfago. B. Aspecto submacroscópico de um PT e de um papiloma (PAP) na base da língua. HE, obj.2,5. 


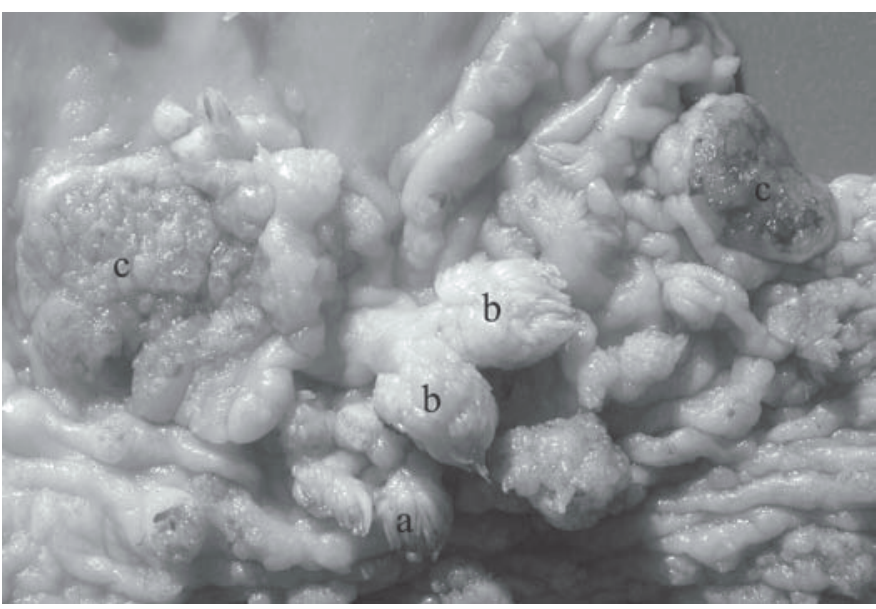

Fig.7. Neoplasias do trato alimentar superior de bovinos associadas ao consumo espontâneo de samambaia, Pteridium aquilinum. Há (a) papilomas, (b) papilomas em transformação para carcinoma de células escamosas (CCE), e (c) CCEs, na entrada do rúmen (Bovino 23).

e paraqueratótica, correspondendo macroscopicamente aos papilomas com projeções digitiformes conspícuas, características desta neoplasia. Os papilomas em fase de regressão (Fig.5C) apresentavam acentuado infiltrado linfocitário no estroma fibrovascular de sustentação e, na maioria das vezes, com atenuação das digitações.

Em 16 bovinos, o exame histológico de lesões macroscopicamente compatíveis com papilomas, porém alguns deles apresentando-se mais arredondados, com projeções digitiformes atenu-

Fig.8. Neoplasias do trato alimentar superior de bovinos associadas ao consumo espontâneo de samambaia, Pteridium aquilinum. Aspectos histológicos dos graus de diferenciação celular dos carcinomas de células escamosas (CCE). A. CCE bem diferenciado com acentuada formação de pérolas de queratina (Bovino 15). HE, obj.10. B. CCE moderadamente diferenciado com moderado pleomorfismo celular e queratinização discreta (Bovino 3). HE, obj. 20. C. CCE pouco diferenciado com acentuado pleomorfismo celular e desmoplasia (Bovino 29). HE, obj.20.

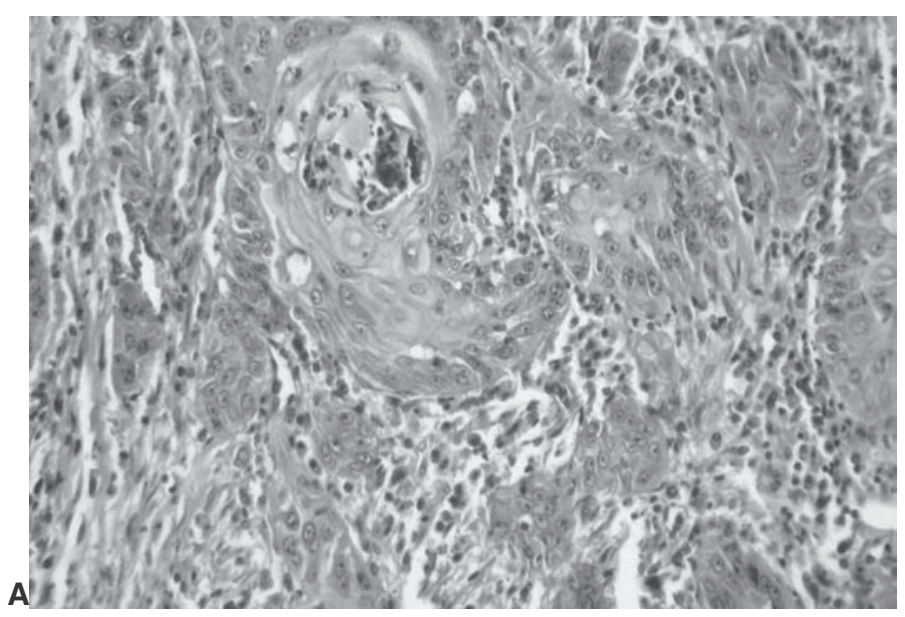

adas (Fig.6A) ou ulceradas, revelou proliferação de queratinócitos neoplásicos malignos a partir da camada basal das digitações, formando ninhos e ilhas que invadiam o estroma fibrovascular preenchendo o tumor (Fig.6B) e estendendo-se à lâmina própria e a outros tecidos subjacentes. Várias dessas ilhas de queratinócitos apresentavam acentuada queratinização lamelar central (pérolas de queratina). Remanescentes de projeções digitiformes eram muitas vezes observadas na superfície desses papilomas em transformação (PTs) para CCEs.

$\mathrm{O}$ aspecto macroscópico dos CCEs era bastante variável, consistindo de massas tumorais exuberantes e de crescimento exofítico, áreas rugosas de crescimento endofítico, ou de espessamentos anelares estenosantes (esses últimos observados somente na parede esofágica). Os CCEs eram freqüientemente ulcerados e a superfície de corte da maioria revelou áreas irregulares de consistência firme, brancas ou com pontos amareloouro (correspondendo à queratinização acentuada). Papilomas e PTs foram freqüentemente observados próximos aos CCEs (Fig.7). Histologicamente, os CCEs eram constituídos por queratinócitos com núcleos vesiculares, redondos, ovóides ou pleomórficos e com um ou mais nucléolos evidentes. $\mathrm{O}$ citoplasma era eosinofílico e abundante. Havia queratinização individual de queratinócitos ou formação de pérolas de queratina. Os CCEs foram classificados como bem (18/30, Fig.8A), moderadamente (4/30, Fig.8B) ou pouco diferenciados (2/30, Fig.8C). Em 6 bovinos com CCEs múltiplos, alguns deles eram bem e outros mode-
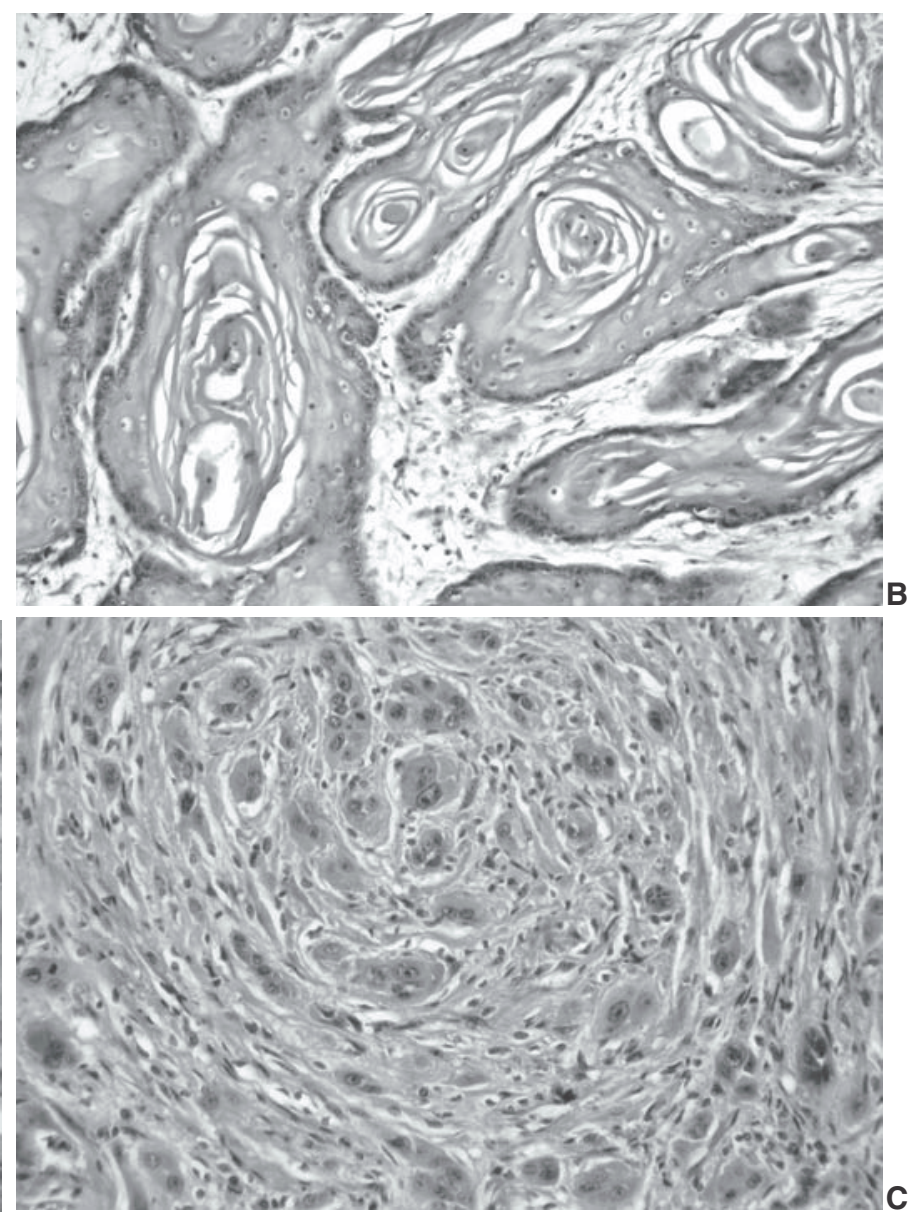




Fig.9. Neoplasias do trato alimentar superior de bovinos associadas ao consumo espontâneo de samambaia, Pteridium aquilinum. Distribuição dos carcinomas de células escamosas (CCEs) no trato alimentar superior (TAS) correlacionando o número total de vezes em que CCEs foram vistos em determinado local (barras listradas) com o número de CCEs de maior extensão naquele mesmo local (barras pretas). $\mathrm{BL}=$ base da língua, $\mathrm{F} / \mathrm{O}=$ faringe/ orofaringe, $\mathrm{EP}=$ epiglote, $\mathrm{ECR}=$ esôfago cranial, $\mathrm{EM}=$ esôfago médio, $\mathrm{EC}=$ esôfago caudal, $\mathrm{ER}=$ entrada do rúmen, $\mathrm{R}=$ rúmen.

radamente diferenciados. Independentemente do grau de diferenciação celular e da localização, os CCEs eram marcadamente invasivos. Nos espessamentos estenosantes anelares esofágicos, os CCEs apresentavam marcada infiltração das camadas muscular e adventícia com acentuada desmoplasia, sendo a mucosa muitas vezes afetada em menor intensidade. Outras alterações histológicas vistas nos CCEs consistiam de calcificação, necrose, edema e hemorragia. Infiltrados multifocais de linfócitos, plasmócitos, macrófagos e eosinófilos foram freqüentemente observados. Áreas de displasia epitelial (lesões pré-neoplásicas) e CCEs in situ ou em fases bem iniciais de desenvolvimento foram freqüientemente observadas no epitélio próximo ou distante aos papilomas e PTs nas diferentes localizações do TAS.

Os CCEs eram únicos (12/30) ou múltiplos (18/30). Na Figura 9 estão correlacionados o número total de vezes em que CCEs de tamanhos variados foram vistos em determinada localização no TAS com o número de CCEs de maior extensão naquele mesmo local. Quando a distribuição dos CCEs de maior extensão foi agrupada em regiões cranial (incluindo base da língua, faringe/ orofaringe, epiglote), média (incluindo os terços cranial, médio e caudal do esôfago) e caudal (incluindo entrada do rúmen e rúmen), observou-se que a localização era cranial em $39 \%$ dos casos, média em $16 \%$, e caudal em $45 \%$. Utilizando-se esse mesmo critério de agrupamento, porém considerando o número total de vezes em que CCEs (de menor e maior extensão) foram diagnosticados nas regiões cranial, média e caudal, os números alteraram-se para $34 \%, 26 \%$ e $40 \%$, respectivamente.

Metástases de CCEs foram observadas em 60\% dos casos, independentemente do grau de diferenciação celular do tumor primário, tendo localização única $(9 / 18)$ ou múltipla $(9 / 18)$. Em 16 casos as metástases foram vistas em linfonodos regionais e em seis casos foram vistas em outros locais como fígado, pulmão, intestino, omento, baço e bexiga. As raras metástases vistas no intestino, omento, baço e bexiga foram de implantação. Um bovino (Bov.22) tinha um nódulo no intestino delgado que correspondia microscopicamente a um adenoma.

\section{DISCUSSÃO}

Os 30 bovinos estudados com CCEs no TAS eram provenientes de propriedades rurais onde a samambaia era abundante nas áreas de pastoreio ou, como no caso de 2 deles, os animais tinham sido adquiridos de propriedades infestadas pela planta. Esta observação epidemiológica reforça os relatos de outros autores para essa forma de intoxicação por samambaia no Brasil (Döbereiner et al. 1967, Tokarnia et al. 1969, 2000) e na GrãBretanha (Pirie 1973, Jarrett 1978, Jarrett et al. 1978). A samambaia requer condições ambientais favoráveis para seu pleno desenvolvimento e proliferação (Tokarnia et al. 1979, Lorenzi 1991, Smith 1999), como as observadas nas propriedades estudadas (solos ácidos e arenosos em encostas de morros). Na maioria delas (18/27) já havia ocorrido pelo menos um caso de CCE no TAS de bovinos no mesmo ano em que foi realizado o questionário ou em anos anteriores, e/ou casos de HEB (7/27), o que indica perdas econômicas consideráveis na região em consequiência da presença de samambaia nas áreas de pastoreio.

A taxa de morbidade foi de $2,7 \%$ e a letalidade pode ser considerada como de $100 \%$, levando-se em consideração que os bovinos que foram submetidos à eutanásia estavam em estágios avançados da doença e certamente iriam morrer dentro de pouco tempo. Estes dados assemelham-se aos descritos na literatura (morbidade de 3\% e letalidade de 100\%) para essa forma de intoxicação no Estado de Santa Catarina (Gava, 1993). A maioria dos bovinos afetados era vacas, porém isso não representa uma predisposição das fêmeas para desenvolverem CCEs no TAS. Este fato pode ser explicado em parte por essa categoria representar a maior parcela da população bovina nas 27 propriedades (41\%), e também porque as vacas assim como os bois (destinados ao trabalho), têm vida mais prolongada que as demais categorias de bovinos, tendo mais chances de desenvolver as lesões desta forma de intoxicação crônica por samambaia, a qual é considerada como dose-dependente, ou seja, os bovinos devem consumir pequenas quantidades de samambaia por vários meses a anos para desenvolverem os CCEs (Tokarnia et al. 2000). A idade variou de 3 a 13 anos, sendo o maior número de casos entre 7 e 8 anos (46,6\%), concordando com a literatura, que destaca uma maior casuística em bovinos acima de 6 anos (Tokarnia et al. 2000), principalmente entre 7 e 8 anos (Gava, 1993). Somente dois bovinos tinham 3 ou 4 anos, porém isso indica que animais mais jovens também podem adoecer.

Os sinais clínicos apresentados pelos bovinos examinados foram semelhantes aos descritos por outros autores (Döbereiner et al. 1967, Tokarnia et al. 1969, 2000, Polack 1990, Gava 1993) e geralmente variaram de acordo com a localização do CCE de maior extensão no TAS, de forma semelhante à descrita anteriormente (Tokarnia et al. 2000), porém verificou-se também a ocorrência de sinais clínicos não diretamente relacionados à localização do maior CCE ou, como no caso da tosse, relacionados com papilomatose digestiva acentuada. Bovinos que tinham CCEs na região cranial do TAS (base da língua, faringe/orofaringe, epiglote) apresentavam mais freqüentemente tosse e sinais clínicos relacionados com distúrbios da apreensão e deglutição de alimentos. Bovinos com tumores ulcerados nestas localizações apresentaram halitose acentuada devido à impactação de alimentos e necrose da massa tumoral. Os CCEs que causavam estenose do 
lúmen esofágico e da entrada do rúmen geralmente eram acompanhados por sinais clínicos relacionados à regurgitação de alimentos ou dificuldades na eructação dos gases da ruminação, levando freqüientemente ao timpanismo. CCEs causando estenose esofágica foram previamente descritos na Escócia e estavam geralmente relacionados com dificuldades na deglutição (Pirie 1973). O curso clínico crônico associado principalmente aos distúrbios mecânicos à ingestão de alimentos deve ter contribuído para o acentuado emagrecimento observado em todos os bovinos intoxicados.

Os achados macroscópicos e histológicos caracterizaram-se principalmente por alterações epiteliais neoplásicas benignas (papilomas) e malignas (PTs e CCEs) nas mesmas localizações ao longo do TAS. Papilomas em várias fases de desenvolvimento foram observados em $97 \%$ dos casos examinados neste estudo, semelhantemente ao que foi relatado na Escócia, onde 96\% dos bovinos tinham esses tumores benignos nas mesmas localizações dos CCEs (Jarrett 1978, Jarrett et al. 1978). Queratinócitos com núcleos excêntricos e citoplasma vacuolizado (denominados de coilócitos ou células do papiloma) localizados logo abaixo da camada córnea têm sido descritos em papilomas de origem viral do TAS de bovinos (Jarret et al. 1978, Head et al. 2002) e foram também observados nos casos aqui descritos. Entretanto, corpúsculos de inclusão intranucleares em queratinócitos não foram vistos no presente estudo. A etiologia viral dos papilomas alimentares foi estabelecida pela demonstração de grandes corpúsculos de inclusão intranucleares em queratinócitos de alguns papilomas (Jarrett 1978, Jarrett et al. 1978), pela evidenciação de partículas virais correspondentes a um papilomavírus na microscopia eletrônica (Jarrett 1978), e pela detecção do DNA do BPV-4 (Campo et al. 1985, 1994).

Quanto à distribuição dos CCEs nas regiões craniais, médias e caudais do TAS, observou-se alteração nas percentagens quando considerados somente os tumores de maior tamanho e quando considerou-se o número total de vezes em que CCEs de tamanhos variados foram diagnosticados nas diferentes regiões. As menores variações nas percentagens foram observadas nas regiões cranial (de $39 \%$ para $34 \%$ ) e caudal (de $45 \%$ para $40 \%$ ) e a maior variação foi vista na média (de $16 \%$ para $26 \%$ ), respectivamente. Isto confirma que a distribuição dos CCEs no TAS não é constante, tendo sido observados diferentes percentuais de frequiência de aparecimento deste tumor em diferentes estudos (Jarrett 1978, Jarrett et al. 1978, Gava et al. 2002). Revela também uma percentagem elevada de CCEs pequenos principalmente no esôfago, os quais possivelmente passam despercebidos, no caso de apenas serem colhidos e examinados os tumores de maiores proporções.

Microscopicamente, os CCEs examinados no presente estudo tinham características semelhantes às descritas anteriormente (Döbereiner et al. 1967, Tokarnia et al. 1969, Jarrett 1978, Polack 1990). A grande maioria era bem diferenciada e com abundante queratinização. Um achado interessante foi o freqüiente infiltrado inflamatório eosinofílico no estroma conjuntivo dos CCEs. Infiltrados de eosinófilos foram observados anteriormente em CCEs do TAS de bovinos intoxicados por samambaia (Polack 1990), porém sua presença não foi discutida. Eosinófilos têm sido constantemente observados em CCEs de laringe em humanos (Ercan et al. 2005, Said et al. 2005) e foram correlacionados com um maior potencial de invasão tumoral (Said et al. 2005) ou com a idade dos pacientes, sendo mais freqüientes em pessoas acima de 60 anos (Ercan et al. 2005). $O$ papel dos eosinófilos nos CCEs de bovinos intoxicados por samambaia não está definido e poderá vir a ser investigado. Metástases de CCEs foram observadas independentemente do grau de diferenciação celular dos CCEs primários e a percentagem foi de $60 \%$; superior aos relatos anteriores que reportaram metástases em 20-40\% dos casos (Jarrett 1978, Jarrett et al. 1978, Head et al. 2000).

Somente em um bovino foi observada uma lesão nodular no intestino, que correspondia histologicamente a um adenoma. Lesões nodulares múltiplas (adenomas ou pólipos adenomatosos, placas sésseis compostas de epitélio hipercromático, lesões marcadamente proliferativas na ampola de Vater, e adenocarcinomas) foram relatadas nos intestinos de $56 \%$ de 80 bovinos examinados com CCEs no TAS (Jarrett et al. 1978). Entretanto, papilomas não foram relatados no intestino. Somente um bovino deste estudo tinha um papiloma na mucosa da bexiga, o que difere do descrito na literatura que relata a freqüiente coexistência entre CCEs no TAS e tumores na bexiga relacionados a HEB (Döbereiner et al. 1967, Tokarnia et al. 1969, 2000, Jarrett et al. 1978, Polack 1990, Souza \& Graça 1993). Baseado no questionário epidemiológico, a ocorrência de HEB nas propriedades estudadas é bem menos expressiva naquela região do que a ocorrência de CCEs no TAS associada ao consumo de samambaia, concordando com os autores que observaram que as diferentes formas clínicas da intoxicação por samambaia não ocorrem com a mesma freqüência nas diversas regiões (Tokarnia et al. 1969).

Ficou evidente através dos resultados deste trabalho que há uma amplificação no número de papilomas em bovinos pastoreando samambaia, pois na rotina de necropsias de bovinos no LPV-UFSM, papilomas são raramente vistos e quando são, geralmente estão em pequeno número em bovinos provenientes de áreas sem samambaia, fato que também foi observado em bovinos de matadouro na Escócia (Jarrett 1985). Esta amplificação tem sido explicada (Jarrett et al. 1978, Jarrett 1978, 1985) pelos efeitos imunossupressores da samambaia (Evans 1968, Campo et al. 1994). Foi também demonstrado através de estudo experimental que a ingestão prolongada de samambaia deprime o mecanismo de regressão espontânea dos papilomas permitindo que os mesmos permaneçam no TAS por vários anos (Jarrett 1985). Entretanto, vale salientar que papilomas com características histológicas típicas da fase de regressão, com infiltrados linfocitários marcados (Knowles et al. 1996), foram observados em vários dos bovinos deste estudo, indicando que não há uma total inibição dos mecanismos de regressão espontânea dos papilomas, mas talvez haja um retardamento neste processo. Com a permanência dos papilomas por mais tempo, a proliferação epitelial acentuada induzida pelo BPV-4 proveria um alvo celular amplificado para a ação dos co-carcinógenos químicos presentes na samambaia (Campo et al. 1994, Campo 1997, 2002).

A presença de papilomas em transformação (PTs) para CCEs em mais da metade dos bovinos estudados foi um dos achados mais importantes deste estudo. Os PTs estavam localizados pró- 
ximos a papilomas ou CCEs e apresentavam aspectos histológicos convincentes da malignização desta neoplasia inicialmente benigna. Essas são evidências morfológicas indiscutíveis da transformação de papilomas em CCEs no TAS, como descritas anteriormente (Jarrett 1978, Jarrett et al. 1978). A presença do DNA do BPV-4 não tem sido considerada necessária para a manutenção do estado maligno dos CCEs (Campo et al. 1985, 1994). Uma explicação para a ausência do DNA viral nos CCEs alimentares é a de que o papel do BPV-4 na carcinogênese estaria confinado aos primeiros estágios de transformação celular (Campo et al. 1994). Uma das grandes diferenças entre o potencial oncogênico do BPV-4 e do papilomavírus humano (HPV), é que o BPV-4 não possui o gene E6 (Jackson et al. 1991), o qual contribui grandemente para a transformação celular observada na infecção pelo HPV-16 (Pennie et al. 1993).

$\mathrm{O}$ sinergismo entre a infecção por BPV-4 e a exposição à quercetina, um flavonóide carcinogênico presente na samambaia (Pamucku et al. 1980, Musonda \& Chipman 1999) na transformação celular foi estabelecido em estudos in vitro (Pennie \& Campo 1992, Cairney \& Campo 1995, Connolly et al. 1998, Beniston et al. 1999, 2001). Entretanto, a comprovação deste sinergismo in vivo não foi completa, pois bovinos infectados pelo BPV-4 e tratados somente com quercetina não apresentaram malignização dos papilomas (Campo et al. 1994). A explicação dada para esse fato foi a de que os bovinos permaneceram imunocompetentes, eliminando qualquer célula transformada (maligna) através de mecanismos de imunovigilância, confirmando a necessidade da imunossupressão conferida por outros princípios tóxicos da samambaia na patogenia dos CCEs, pois a quercetina não é imunossupressora (Campo et al. 1994).

Em outros estudos foi difícil afirmar se todos os CCEs originavam-se de papilomas pré-existentes ou se também havia transformação maligna simultânea do epitélio previamente normal (Jarrett et al. 1978, Jarrett 1980) devido à ação do carcinógeno sobre ambos, papilomas e epitélio normal (Jarret 1980). Através do encaminhamento dirigido de áreas rugosas na mucosa do TAS, principalmente da mucosa esofágica, foi possível observar microscopicamente alterações pré-neoplásicas (áreas de displasia) e áreas de CCE in situ ou CCEs em estágios bem iniciais de desenvolvimento independentemente da presença de papilomas no local, mostrando claramente ser possível o desenvolvimento de CCEs diretamente do epitélio normal. Adenomas e adenocarcinomas foram também relatados no intestino de bovinos com CCEs no TAS, sem associação com papilomas naquela localização (Jarrett et al. 1978). Estes aspectos são muito importantes na patogênese dos CCEs, pois indicam que além das possíveis interações BPV-4-samambaia (Campo et al. 1994, Campo 1997, 2002) deve haver uma ação direta da carcinogênese química da samambaia, possivelmente do ptaquilosídeo norsesquiterpeno (Fenwick 1988, Smith et al. 1999, Villalobos-Salazar et al. 1999), no desenvolvimento pelo menos de parte dos CCEs digestivos.

\section{REFERÊNCIAS}

Barros C.S.L. \& Marques G.H.F. 2003. Procedimentos para o diagnóstico das doenças do sistema nervoso central de bovinos. Departamento de Defesa Animal, Ministério da Agricultura, Pecuária e Abastecimento, Brasília. 50p. Disponível na internet: http://www.agricultura.gov.br
Beniston R.G., Morgan M.I., O’Brien V. \& Campo M.S. 1999. Synergy between papillomavirus and quercetin significance of quercetin-induced $\mathrm{C} 1$ arrest for cellular transformation. IV Int. Bracken Group Conf. - Bracken fern: toxicity, biology and control. Manchester, p.123-127.

Beniston R.G., Morgan M.I., O’Brien V. \& Campo M.S. 2001. Quercetin, E7 and p53 in papillomavirus oncogenic cell transformation. Carcinogenesis 22 (7):1069-1076.

Cairney M. \& Campo M.S. 1995. The synergism between bovine papillomavirus type 4 and quercetin is dependent on the timing of exposure. Carcinogenesis 16:1997-2001.

Campo M.S. Review: bovine papillomavirus and cancer. 1997. Vet J. 154:175188.

Campo M.S. 2002. Animal models of papillomavirus pathogenesis. Virus Res. 89:249-261.

Campo M.S., Moar H.M., Sartirana M.L., Kennedy I.M \& Jarrett W.F. 1985. The presence of bovine papillomavirus type 4 DNA is not required for the progression to, or the maintenance of the malignant state in cancers of the alimentary canal in cattle. EMBO J. 4 (7):1819-1825.

Campo M.S., O’Neil, B.W., Barron R.J \& Jarrett W.F.H. 1994. Experimental reproduction of the papilloma-carcinoma complex of the alimentary canal in cattle. Carcinogenesis 15 (8):1597-1601.

Campos Neto O., Barros H.M. \& Bicudo P.L. 1975. Estudo do carcinoma do trato digestivo superior e da hematúria enzoótica dos bovinos na região de Botucatu, Estado de São Paulo. Arqs Esc. Vet. UFMG 27:125-133.

Connolly J.A., Morgan I.M., Jackson M.E. \& Campo M.S. 1998. The BPV-4 co-carcinogen quercetin induces cell cycle arrest and up-regulates transcription from the LCR of BPV-4. Oncogene 16:2739-2746.

Döbereiner J., Tokarnia C.H. \& Canella C.F.C. 1967. Ocorrência de hematúria enzoótica e de carcinomas epidermóides no trato digestivo superior em bovinos no Brasil. Pesq. Agropec. Bras. 2:489-504.

Ercan I., Çakir B., Basak T. Özdemir T. \& Sayin I. 2005. Prognostic significance of stromal eosinophilic infiltration in cancer of the larynx. 27th Nat. Otorhinolaryng. Head and Neck Surg. Cong., Turkey, p.869-873.

Evans I.A. 1968. The radiomimetic nature of bracken toxin. Cancer Res. 28:2252-2261.

Fenwick G.R. 1988. Bracken (Pteridium aquilinum) toxic effects and toxic constituents. J. Sci. Food Agric. 46:147-173.

França T.N., Tokarnia C.H. \& Peixoto P.V. 2002. Enfermidades determinadas pelo princípio radiomimético de Pteridium aquilinum (Polypodiaceae). Pesq. Vet. Bras. 22(3):85-96.

Freitas R.N., Silva, M.E., O’Connor P.J. \& Povei A.C. 1999. ${ }^{32}$ P-postlabeling analysis of DNA adducts in tissues obtained from rats treated with bracken fern (Pteridium aquilinum subsp. caudatum) from Brazil. IV Internat. Bracken Group Conf. - Bracken fern: toxicity, biology and control. Manchester, p.132-135.

Gava A. 1993. Intoxicação por Pteridium aquilinum, p.247-258. In: RietCorrea F., Méndez M.C. \& Schild A.L. (ed.) Intoxicações por Plantas e Micotoxicoses em Animais Domésticos. Hemisfério Sul, Pelotas.

Gava A., Neves D.S., Gava D., Saliba T.M., Schild A.L \& Riet-Correa F. 2002. Bracken fern (Pteridium aquilinum) poisoning in cattle in southern Brazil. Vet. Hum. Toxicol. 44: 362-365.

Head K.W., Else R.W. \& Dubielzig R.R. 2002. Tumours of the alimentary tract. p.444-448. In: Meuten D.J. (ed.) Tumours of Domestic Animals. Iowa State University Press, Ames.

Jackson M.E, Pennie W.D, McCaferry F.E., Smith K.T., Grindlay G.J. \& Campo M.S. 1991. The B subgroup bovine papillomaviruses lack an identifiable E6 open reading frame. Mol. Carc. 4:382-387.

Jarrett W.F.H. 1978. Transformation of warts to malignancy in alimentary carcinoma of cattle. Bull. Cancer 65:191-194.

Jarrett W.F.H. 1980. Bracken fern and papillomavirus in bovine alimentary cancer. Brit. Med. Bull. 36(1):79-81.

Jarrett W.F.H. 1985. The natural history of bovine papillomavirus infections. Adv. Viral Oncol. 5:83-102. 
Jarrett W.F.H., McNeil P.E., Grimshaw W.R.T., Selman I.E. \& McIntyre I.M. 1978. High incidence area of cattle cancer with a possible interaction between an environmental carcinogen and a papillomavirus. Nature 274:215-217.

Knowles G., O’Neil B.W. \& Campo M.S. 1996. Phenotypic characterization of lymphocytes infiltrating regressing papillomas. J. Virol. 70:8451-8458.

Lorenzi H. 1991. Plantas Daninhas do Brasil: terrestres, aquáticas, parasitas, tóxicas e medicinais. $2^{\mathrm{a}}$ ed., Plantarum, São Paulo, p.352.

Mckee P.H. 1999. Essential Skin Pathology. Mosby, London, p.141-152.

Musonda C.A. \& Chipman J.K. 1999. Carcinogenic and anti-carcinogenic potential of quercetin. IV Int. Bracken Group Conf. - Bracken fern: toxicity, biology and control. Manchester, p.106-115.

Pamukcu A.M., Yalçiiner S., Hatcher J.F. \& Bryan G.T. 1980. Quercetin, a rat intestinal and bladder carcinogen present in bracken fern (Pteridium aquilinum). Cancer Res. 40:3468-3472.

Pennie W.D. \& Campo M.S. 1992. Synergism between bovine papillomavirus type 4 and the flavonoid quercetin in the cell transformation in vitro. Virol. 190:861-865.

Pennie W.D., Grindlay G.J., Cairney M. \& Campo M.S. 1993. Analysis of the transforming functions of BPV-4. Virol. 193:614-620.

Pirie H.M. 1973. Unusual occurrence of squamous carcinoma of the upper alimentary tract in cattle in Britain. Res. Vet. Sci. 15:135-138.

Polack E.W. 1990. Toxicidade de Pteridium aquilinum (L.) Kuhn no Estado do Paraná: estudo epidemiológico e anátomo-patológico e utilização da técnica de peroxidade-antiperoxidase na pesquisa do papilomavírus em lesões atribuídas à ingestão da planta em bovinos. Dissertação (Mestrado), Curso de Pós-Graduação em Ciências Veterinárias, UFPR, Curitiba. 102p.

Said M., Wiseman S., Yang J., Alrawy S., Douglas W., Cheney R., Hicks W.,
Rigual N., Noree T., Spiegel G. \& Tan D. 2005. Tissue eosinophilia: a morphologic for assessing stromal invasion in laryngeal squamous neoplasms. BMC Clin. Pathol. 5(1):1-8.

Smith R.T. 1999. The spread of bracken: an end-of-century assessment of factors, risks and land use realities. IV Int. Bracken Group Conf. - Bracken fern: toxicity, biology and control. Manchester, p.2-8.

Smith B.L., Lauren D.R. \& Prakash A.S. 1999. Bracken fern (Pteridium): Toxicity in animal and human health. IV Int. Bracken Group Conf. Bracken fern: toxicity, biology and control. Manchester, p.76-85.

Souza M.V. \& Graça D.L. 1993. Intoxicação crônica por Pteridium aquilinum (L.) Kuhn (Polypodiaceae) em bovinos. Ciência Rural, Santa Maria, 23(2):203-207.

Tokarnia C.H., Döbereiner J. \& Canella C.F.C. 1967. Ocorrência da intoxicação aguda pela "samambaia" (Pteridium aquilinum (L.) Kun) em bovinos no Brasil. Pesq. Agropec. Bras. 2:329-336.

Tokarnia C.H., Döbereiner J. \& Canella C.F.C. 1969. Ocorrência de hematúria enzoótica e de carcinomas epidermóides no trato digestivo superior em bovinos no Brasil. II. Estudos complementares. Pesq. Agropec. Bras. 4:209-224.

Tokarnia C.H., Döbereiner J. \& Silva M.F. 1979. Plantas Tóxicas da Amazônia a Bovinos e outros Herbívoros. Instituto Nacional de Pesquisas da Amazônia, Manaus, p.48-57.

Tokarnia C.H., Döbereiner J. \& Peixoto P.V. 2000. Plantas de ação radiomimética, p.178-187. In: Tokarnia C.H., Döbereiner J. \& Peixoto P.V. (ed.) Plantas Tóxicas do Brasil. Editora Helianthus, Rio de Janeiro.

Villalobos-Salazar J., Hernández H., Meneses A. \& Salazar G. 1999. Factors which may affect ptaquiloside levels in milk: effects of altitude, bracken fern growth stage, and milk processing. IV Int. Bracken Group Conf. Bracken fern: toxicity, biology and control. Manchester, p.68-74. 